\title{
Application of bacterial foraging algorithm in the allocation of DSTATCOM in 50-bus canteen feeder
}

\author{
Umar Musa $^{1 *}$, Abdullahi A. Mati ${ }^{1,2}$ and Yuvaraj T. ${ }^{3}$ \\ ${ }^{1}$ Department of Electrical Engineering, Ahmadu Bello University, PMB 1045, Zaria, Kaduna, Nigeria. \\ ${ }^{2}$ Center for Energy Research and Training (CERT), Ahmadu Bello University, PMB 1045, Zaria, Kaduna, Nigeria. \\ ${ }^{3}$ Department of EEE, Saveetha School of Engineering, Saveetha Institute of Medical and Technical Sciences, Chennai, India. \\ *Corresponding author: umusa@abu.edu.ng, Tel: +234-7030803441
}

\begin{abstract}
Voltage instability has been identified as the most critical factor responsible for poor power quality in electric power systems. The high losses experienced at the distribution level of these systems has become a major concern to power system operators, with about $10-13 \%$ of the total generation being dissipated as heat. Maintaining the system voltage within an acceptable limit will go a long way in reducing these losses and enhancing the overall system operational capability. The objective of this paper is to improve the voltage magnitude and reduce overall power losses in an existing 50-bus radial distribution feeder via the allocation of Distribution Static Compensator (DSTATCOM) using an established bacterial foraging algorithm (BFA) based model. The application of the swarm-based meta-heuristic model is extended to a three-quarter (75\%) loading condition of the standard IEEE 33-bus test network and then, employed on the 50-bus Canteen feeder for both normal $(100 \%)$ and three-quarter (75\%) loading conditions. Comprehensive analysis was performed for both networks and the results were compared with their respective base-case scenarios. The final results of the evaluation obtained through simulation showed appreciable reduction in power losses and improvement in overall voltage profile with the allocation of DSTATCOM in both networks using the BFA based model. Voltage improvement in the region of $20.04 \%$ and active power loss reduction of $24.86 \%$ were recorded for three-quarter loading of the IEEE test network. For the 50-bus Canteen feeder, an overall voltage profile improvement of $6.13 \%$ and active power loss reduction of $22.84 \%$ were achieved for normal loading condition, whereas $2.99 \%$ and $19.71 \%$ improvement in total voltage profile and active power loss respectively were attained under three-quarter loading condition.
\end{abstract}

Keywords: Distribution Static Compensator, Bacterial Foraging Algorithm, Loss Minimization, Voltage Profile, Canteen Feeder.

Article History: received 12 January 2019; accepted 8 April 2019; published 25 April 2019.

(C) 2019 Penerbit UTM Press. All rights reserved

\section{NOMENCLATURE}

$i, k \quad$ bus indices

$V_{\text {ref }} \quad$ reference voltage

$V_{\min } \quad$ minimum voltage

$V_{\max } \quad$ maximum voltage

$V_{i} \quad$ voltage magnitude at bus $\mathrm{i}$

$V_{k} \quad$ voltage magnitude at bus $\mathrm{k}$

$R_{i} \quad$ resistance of line section between bus $\mathrm{i}$ and $\mathrm{i}+1$

$X_{i} \quad$ reactance of line section between bus $\mathrm{i}$ and $\mathrm{i}+1$

$P_{i} \quad$ active power at bus $\mathrm{i}$

$Q_{i} \quad$ reactive power at bus i

$P_{D, i} \quad$ active power demand at bus i

$Q_{D, i} \quad$ reactive power demand at bus i

$P_{\text {slack }} \quad$ active power injected from slack bus

$Q_{\text {slack }} \quad$ reactive power injected from slack bus

$Q_{c, \text { min }} \quad$ minimum size of DSTATCOM

$Q_{c, \text { max }}$ maximum size of DSTATCOM

$Q_{c, i} \quad$ size of DSTATCOM at bus i

$N \quad$ bus number

$N B \quad$ branch number

$N C \quad$ number of DSTATCOM

\section{INTRODUCTION}

Electric power system is a compact arrangement of three major components namely: generation, transmissions and distribution systems [1]. In order to meet consumers' demand, the generation systems are normally expanded with growing customer demand. However, it is no secret that electric power systems all over the world are experiencing exponential rise in power demand by electricity consumer, thereby forcing power systems to be operated close to their tolerance [2]. This action is capable of jeopardizing the system security and if not properly handled may lead to system collapse [3]. Expansion of existing power networks and setting up of new ones will go a long way in addressing the problem of swelling power demand. However, unfavorable governmental policies, coupled with environmental, financial and time factors are the major drawbacks encountered [4].

Currently, Distribution Flexible AC Transmission Systems (D-FACTS) devices are widely employed at the distribution level of power systems to enhance consumers' energy supply [5]. The placement of one or 
more D-FACTS devices in distribution networks can improve the system voltage profile and reduce its losses. Examples of D-FACTS devices developed and employed for enhancing power systems performance include Universal Power Quality Conditioner (UPQC), Dynamic Voltage Restorer (DVR), Distribution Static Synchronous Series Compensator (DSSSC), Distribution Static Compensator (DSTATCOM), etc [2].

The DSTATCOM is a shunt connected D-FACTS device that has, to a great extent, gained recognition among researchers and power system operators due to its high regulatory capability, low power losses, compact size, less harmonic distortion, zero resonance and low-cost [6]. Although there is high interest in the application of DSTATCOM for improving the operational capability of existing power systems, proper placement of these devices in distribution networks is tasking and requires a robust approach [2].

Many works have employed several techniques for optimal allocation of DSTATCOMS in distribution networks. The use of analytical approaches to overcome the issues of power loss and voltage deviation in distribution networks by DSTATCOM have been reported in [1], [7], [8], [9], [10] and [11].However, these techniques are insufficient due to their inability to fully integrate the network nonlinear characteristics, their mathematical complexity and high computational time [12]. Thus, the need for less complex, fast computational time and more effective approaches.

The drawbacks encountered by analytical approaches in DSTATCOM allocation have been addressed to a large extent by several meta-heuristic techniques such as crow search algorithm [13], hybridized PSO and general algebraic modeling system [14], differential evolution algorithm [15, 16], imperialistic competitive algorithm [17], cuckoo search algorithm [18], hybridized fuzz-ACO [19], particle swarm optimization algorithm [20], immune algorithm [21], harmony search algorithm [5], bacterial foraging algorithm [4], quadratic adaptive bacterial foraging algorithm [6], firefly algorithm [22], grasshopper optimization algorithm [2] and weighted artificial fish swarm algorithm [23].

Although all of these methods have been used to optimally locate and size single or multiple DSTATCOMs in different distribution networks, their effectiveness on existing distribution networks cannot be guaranteed, as their applications have been restricted mostly to standard test networks. Hence, employing such techniques in solving local existing network problems is highly necessary.

Considering the aforementioned limitations, this paper which is an extension of the original work presented in [3] focuses on evaluating the effectiveness of bacterial foraging algorithm in the optimal allocation of DSTATCOM in an existing 50-bus Canteen feeder under normal and three-quarter loading conditions with the intent of enhancing voltage stability and reducing losses, while at the same time satisfying the feeder's constraints.

\section{PROBLEM FORMULATION}

\subsection{Radial Distribution Power Flow Analysis}

An elaborate power flow analysis of radial distribution systems is adopted from [2] based on a simple distribution network illustrated in figure 1 .

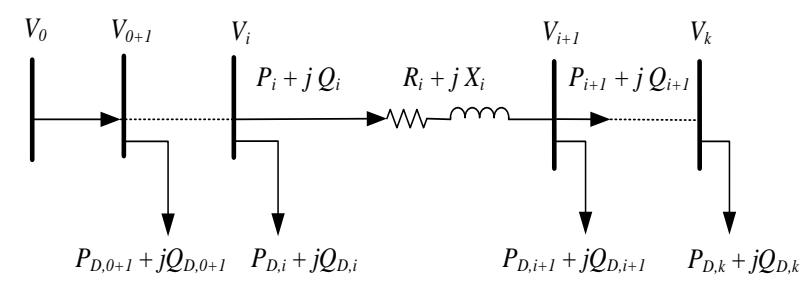

Figure 1. Single line diagram of radial distribution network

The network power flow equations obtained from figure 1 are given as:

$$
\begin{gathered}
P_{i+1}=P_{i}-P_{D, i+1}-R_{i}\left(\frac{P_{i}^{2}+j Q_{i}^{2}}{\left|V_{i}\right|^{2}}\right) \\
Q_{i+1}=Q_{i}-Q_{D, i+1}-X_{i}\left(\frac{P_{i}^{2}+j Q_{i}^{2}}{\left|V_{i}\right|^{2}}\right) \\
V_{i+1}^{2}=V_{i}^{2}-2\left(R_{i} P_{i}+X_{i} Q_{i}\right)+\left(R_{i}^{2}+X_{i}^{2}\right)\left(\frac{P_{i}^{2}+j Q_{i}^{2}}{\left|V_{i}\right|^{2}}\right)
\end{gathered}
$$

The power losses (active and reactive) between buses $i$ and $i+1$ are given expressed as:

$$
\begin{aligned}
& P_{\text {Loss }(i, i+1)}=R_{i}\left(\frac{P_{i}^{2}+j Q_{i}^{2}}{\left|V_{i}\right|^{2}}\right) \\
& Q_{\text {Loss }(i, i+1)}=X_{i}\left(\frac{P_{i}^{2}+j Q_{i}^{2}}{\left|V_{i}\right|^{2}}\right)
\end{aligned}
$$

The total network active and reactive power losses represented by equations (6) and (7) are computed by taking the summation of individual active and reactive power losses for $n=1,2,3, \ldots, \mathrm{NB}$ using equations (4) and (5).

$$
\begin{aligned}
& P_{\text {Loss }(\text { Total })}=\sum_{n=1}^{N B} P_{\text {Loss }, n} \\
& Q_{\text {Loss (Total) }}=\sum_{n=1}^{N B} Q_{\text {Loss }, n}
\end{aligned}
$$

The overall voltage profile of the system can be improved by reducing the network voltage deviation expressed by: 


$$
V_{D}=\sum_{i}^{N}\left(V_{i}-V_{r e f}\right)^{2}
$$

\subsection{Objective Function}

The objective of allocating DSTATCOM in distribution networks is to reduce power losses and enhance voltage profile, while at the same time satisfying the network constraint. In order to achieve the stated objective, a multiobjective function $(F)$ comprising of total active power loss and voltage deviation is minimized as demonstrated in equation (9) subject to the equality and inequality constraints presented in equations (10)-(11) and (12)-(13) respectively.

$$
\begin{aligned}
& \operatorname{Minimize}(F)=\operatorname{Minimize}\left(P_{\text {Loss (Total })}+V_{D}\right) \\
& P_{\text {slack }}=\sum_{i=1}^{N} P_{D, i}+\sum_{n=1}^{N B} P_{\text {Loss }, n} \\
& Q_{\text {slack }}+\sum_{i=1}^{N C} Q_{\mathrm{c}, i}=\sum_{i=1}^{N} Q_{D, i}+\sum_{n=1}^{N B} Q_{\text {Loss }, n} \\
& V_{\text {min }} \leq V_{i} \leq V_{\max } \\
& Q_{c, \min } \leq Q_{c, i} \leq Q_{c, \max }
\end{aligned}
$$

\section{STRUCTURE OF THE OPTIMIZATION ALGORITHM}

The BFA is a swarm-based nature inspired algorithm that mimics the food searching strategy of Escherichia Coli bacteria [24-27]. The algorithm is designed based on four main operations explained succinctly as below:

\subsection{Chemotaxis}

Chemotaxis explains the movement of bacteria toward nutrients or away from noxious substances over a search space [28, 29]. When situated in highly nutrition environment, a bacterium maintain its movement by swimming in the same direction. However, if its current position is less nutritious, the bacterium changes direction by tumbling in anticipation of finding nutrients [28]. The movement of the $i^{\text {th }}$ bacterium over a landscape of nutrients is described by:

$$
\theta^{i}(j+1, k, l)=\theta^{i}(j, k, l)+C(i) \phi(i)
$$

where $\theta^{i}(j, k, l)$ is the location of $i^{\text {th }}$ bacterium at $j^{\text {th }}$ chemotactic, $k^{\text {th }}$ reproductive, $l^{\text {th }}$ elimination-dispersal step. $C(i)$ is the length of unit walk and $\phi(i)$ is the direction angle of the $j^{\text {th }}$ step $[6,12]$. The cost function of the $i^{t h}$ bacterium represented by $J=J(i, j, k, l)$ is obtained based on its position [24]. The direction angle $\phi(i)$ describes the tumble of the bacteria expressed as:

$$
\phi(i)=\frac{\Delta(i)}{\sqrt{\Delta^{T}(i) \Delta(i)}}
$$

where $\Delta(i) \epsilon \square^{p}$ is a randomly generated vector with elements within the interval $[-1,1]$, while $\square$ and $p$ represent real numbers and dimensions respectively.

\subsection{Swarming}

Bacterium communicate with each other through the secretion of attractants or repellants. A bacterium in nutrient environment release attractants to signal bacteria to swarm together, while repellent are secreted to signal others to maintain a minimum distance when it is in a noxious environment [6], [12], [26]. The cell-to-cell signaling mechanism of the bacteria is explained by:

$$
\begin{aligned}
J_{c c}= & (\theta, P(j, k, l)) \\
= & \sum_{i=1}^{S}\left[-d_{\text {attract }} \exp \left(-\omega_{\text {attract }} \sum_{m=1}^{p}\left(\theta_{m}-\theta_{m}^{i}\right)^{2}\right)\right] \\
& +\sum_{i=1}^{S}\left[h_{\text {repellant }} \exp \left(-\omega_{\text {repellant }} \sum_{m=1}^{p}\left(\theta_{m}-\theta_{m}^{i}\right)^{2}\right)\right]
\end{aligned}
$$

where $J_{c c}$ is the value to be added to the actual cost function, $S$ is the total number of bacteria, $p$ is the number of variables to be optimized which are present in each bacterium, $\theta=\left[\begin{array}{llll}\theta_{1} & \theta_{2} & \ldots & \theta_{p}\end{array}\right]^{T}$ denotes a point in the $p$-dimensional search domain. $d_{\text {attractant }}$ and $\omega_{\text {attractant }}$ are the depth and measure of the width of the attractant released by the cell respectively, while $h_{\text {repellant }}$ and $\omega_{\text {repellant }}$ are the height and measure of the width of the repellent respectively [24].

The effect of equation (16) is considered by determining the fitness of each bacterium using:

$$
J(i, j, k, l)=J(i, j, k, l)+J_{c c}(\theta, P(j, k, l))
$$

\subsection{Reproduction}

The fitness functions are sorted by the reproduction operation explained by equation(18). Half of the bacteria population $\left(S_{r}\right)$ with worst health die off leaving behind those with better fitness. Each of the remaining bacteria split into two in order to maintain the bacteria population. The number of reproduction steps that should be taken by each bacterium is represented by $N_{r e}$.

$$
J_{\text {health }}^{i}=\sum_{j}^{N_{c}+1} J(i, j, k, l)
$$

\subsection{Elimination-Dispersal}

To avoid the possibility of the bacterium being stocked in local optimum and increase the bacterium search ability, some of the bacteria are eliminated while some are dispersed within the search space according to a probability $\left(P_{e d}\right) . N_{e l}$ is the number of eliminationdispersal steps that should be taken by each bacterium $[2,25]$.

A complete pseudo-code of the proposed BFA is presented below [3], [27, 28]:

\footnotetext{
[Step 1] Initialize parameters:

$p, S, N_{s}, N_{c}, N_{r e}, N_{e d}, P_{e d}, C(i), \theta^{i}(i=1,2, \ldots, S)$

[Step 2] Elimination and the dispersal loop:

for $l=l+1$

[Step 3] Reproduction loop:

for $k=k+1$
} 
[Step 4] Chemotaxis loop:

for $j=j+1$

4.1. for each bacterium $i=1,2, \ldots, S$

4.2. Determine the cost function $J(i, j, k, l)$ using equation (17)

4.3. $J_{\text {last }}=J(i, j, k, l)$

4.4. Tumbling: Create a random vector set $\Delta(i) \epsilon \square^{p}$

4.5. Move: Compute $\theta^{i}(j+1, k, l)$ using equation (14)

4.6. Compute cost function $J(i, j+1, k, l)$ using equation (17)

4.7. Swim: $m=0$ (counter for swim length) while $m<N_{S}$

$$
\begin{gathered}
\boldsymbol{m}=\boldsymbol{m}+\mathbf{1}, \\
\text { if } J(i, j+1, k, l)<J_{\text {last }} \text { then } \\
J_{\text {last }}=J(i, j+1, k, l)
\end{gathered}
$$

Move: Compute $\theta^{i}(j+1, k, l)$ using equation (14)

Compute cost function $J(i, j+1, k, l)$ using equation

(17)

else

$m<N_{S} \quad$ end

end

[Step 5] if $j<N_{c}$, move to step 4

[Step 6] Reproduction

for $i=1,2, \ldots, S$,

6.1Compute $J_{\text {health }}^{i}$ using equation (18)

end

6.2 Sort bacteria in order of ascending. The smallest healthier bacteria $\left(S_{r}\right)$ die and others divided into two end bacteria and placed in the same place.

[Step 7] if $k<N_{\text {rego }}$ to step 3

[Step 8] Elimination-dispersal:

for, $m=1,2, \ldots, S$

8.1 if $P_{\text {ed }}>$ rand (create a random number for each bacterium and if any number is lower than $P_{\text {ed }}$ then discard or destroy the bacterium)

Create new random locations for the bacteria else

Bacteria remain in their place.

end

end

if $l<N_{\text {ed, }}$ move back to step 2 ;

else

end.

\section{MATERIALS AND METHOD}

In this paper, a BFA based program code for allocation of DSTATCOM in radial distribution networks is written and implemented in MATLAB 2017a environment using a HP EliteBook 6930p PC with Intel Core Dual P8700 processor, $2.53 \mathrm{GHz}$ and $4 \mathrm{~GB}$ installed RAM. The BFA parameters adopted from [30] are given in table 1. A simple and concise flowchart for implementation of the BFA based optimization approach is illustrated in figure 2.

\section{SIMULATION RESULTS AND DISCUSSION}

The strength of the proposed technique is once again tested on the standard IEEE 33-Bus radial distribution network for three-quarter loading of the network. The network maximum and minimum voltage was set between 1.05 and 0.95p.u respectively as employed in [23]. To test the effectiveness and performance of the approach on existing power distribution networks, a local 50-Bus Canteen feeder with upper and lower bus voltage limits of 1.02 and 0.99 p.u respectively was utilized. Analysis of the feeder with DSTATCOM is carried out for both normal and threequarter loading conditions. The DSTATCOM limit for both networks (IEEE 33-Bus and 50-Bus Canteen feeder) is set between 0 and $100 \%$ of the total $\mathrm{kVAr}$ loadings of the networks.

Table 1. BFA parameters

\begin{tabular}{|c|c|c|}
\hline S/ N & Parameters & Values \\
\hline 1 & Dimension of search space, $p$ & 2 \\
\hline 2 & Number of bacteria, $S$ & 10 \\
\hline 3 & Number of chemotactic steps, $N_{c}$ & 4 \\
\hline 4 & Number of swim steps, $N_{s}$ & 4 \\
\hline 5 & Number of reproductive steps, $N_{r e}$ & 4 \\
\hline 6 & $\begin{array}{c}\text { Number of elimination-dispersal steps, } \\
N_{\text {ed }}\end{array}$ & 3 \\
\hline 7 & $\begin{array}{c}\text { Run-length unit } C_{(} \text {i) } \\
\text { per generation, } S_{r}\end{array}$ & 0.1 \\
\hline 8 & $\begin{array}{c}\text { Number of bacteria reproductions (splits) } \\
S / 2\end{array}$ & 0.25 \\
\hline 9 & $\begin{array}{c}\text { The probability that each bacteria will be } \\
\text { eliminated/dispersed, } P_{\text {ed }}\end{array}$ & 0.1 \\
\hline 10 & Depth of attractant, dattract & 0.2 \\
\hline 11 & Width of attractant, $\omega_{\text {attract }}$ & 0.1 \\
\hline 12 & Height of repellent, $h_{\text {repellant }}$ & 10 \\
\hline 13 & Width of repellent, $\omega_{\text {repellant }}$ & \\
\hline
\end{tabular}

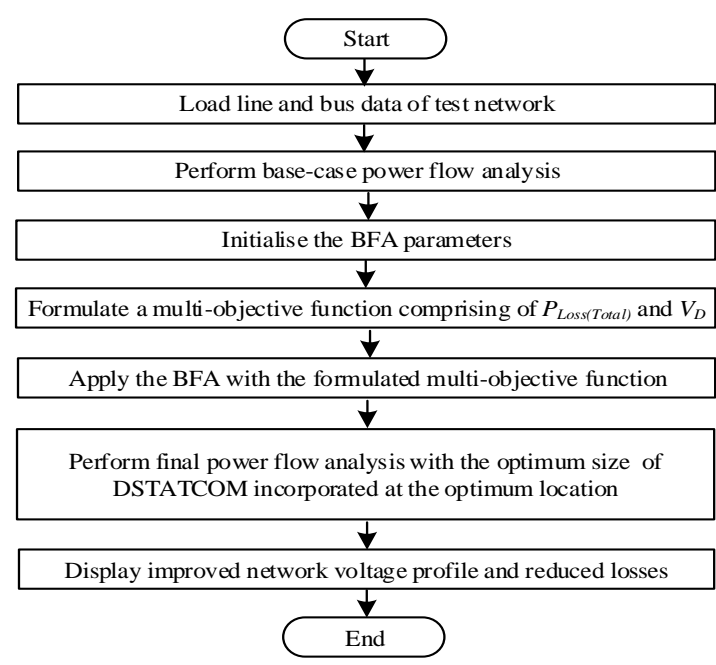

Figure 2. Flow chart for proposed BFA approach

\subsection{3-Bus Standard Test Network}

The network which consists of 33-buses and 32branches has substation voltage, base MVA and overall real and reactive loads values of $12.66 \mathrm{kV}, 100 \mathrm{MVA}$, 3.72MW and 2.3MVAr respectively. The network single line diagram and data (line and bus) employed in this work can be obtained from [21].

As reported in [3], the BFA approach has been applied for DSTATCOM placement under normal loading condition of the test network to minimize total active power loss and voltage deviation as described in equation(9). It was reported that a single DSTATCOM with average optimal size of $2577 \mathrm{kVAr}$ was placed at bus 30 using the proposed method. This action has succeeded in raising the minimum voltage value at bus 18 from 0.9134 to 0.9428 p.u., thereby improving the 
overall voltage profile of the network by $82.88 \%$ as compared to the base-case. A clear comparison in terms of voltage profile improvement is shown in figure 3.

Figures 4 and 5 shows the reduction in active and reactive power losses caused by the presence of DSTATCOM in the network. The total active and reactive losses have been reduced from $201.8925 \mathrm{~kW}$ and $134.613 \mathrm{kVAr}$ to $190.5254 \mathrm{~kW}$ and $132.6283 \mathrm{kVAr}$ respectively, thus resulting in 5.87 and $1.50 \%$ reduction respectively as compared to the base-case. Also, the incorporation of DSTATCOM by the proposed method has further enhanced the network mean voltage magnitude from 0.9486 to 0.9752 .

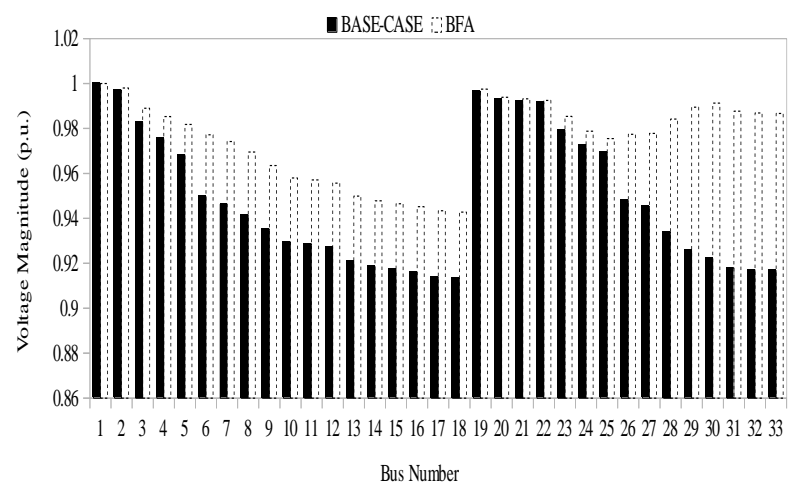

Figure 3. Voltage profile improvement using BFA

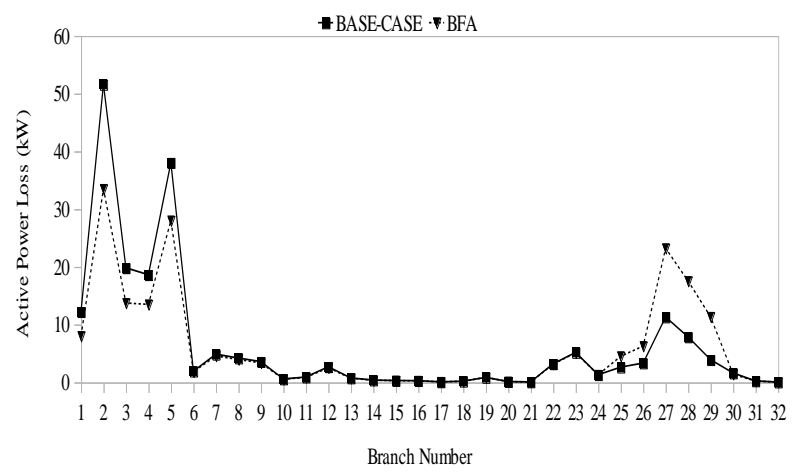

Figure 4. Active power loss reduction using BFA

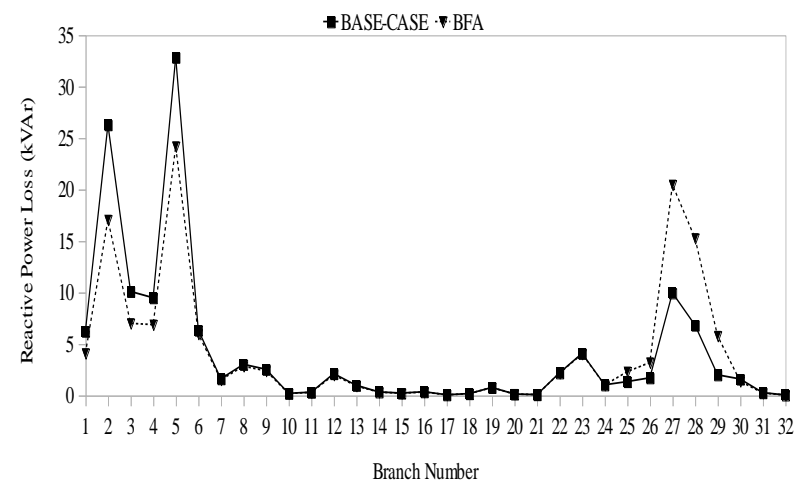

Figure 5. Reactive power loss reduction using BFA

For three-quarter loading condition of the test network, the position and size of DSTATCOM were determined as bus 29 and $883 \mathrm{kVar}$ respectively. The placement of the obtained DSTATCOM size on the optimum bus has improved the minimum bus voltage profile from 0.9036 to $0.9431 \mathrm{p} . \mathrm{u}$, as such enhancing the overall network voltage profile by $20.0 \%$ as compared to the base-case. Figure 6 shows a plot illustrating the improvement achieved due to the installation a DSTATCOM in the network.

The effect of the DSTATCOM in terms of the network active and reactive power losses can be seen in figures 7 and 8 respectively. The presence of the compensator has reduced the active and reactive losses by 24.89 and $25.12 \%$ respectively as compared to the network base-case results. In addition, the mean voltage magnitude has improved from 0.9621 to 0.9682 with the allocation of DSTATCOM in the network.

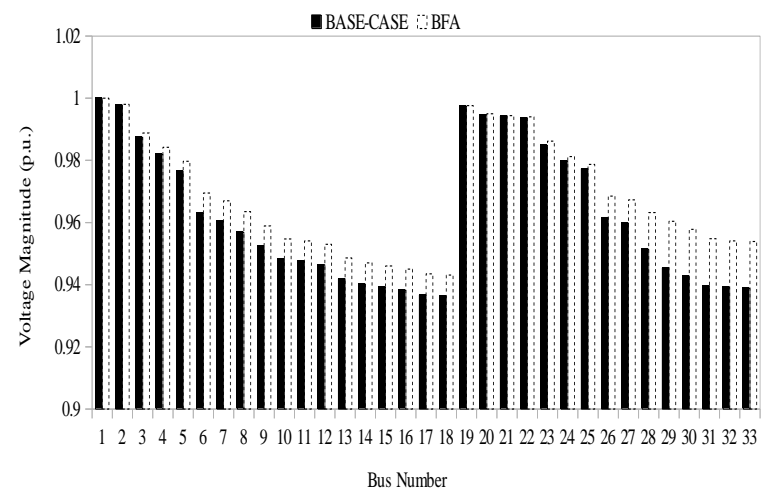

Figure 6. Voltage profile improvement using BFA

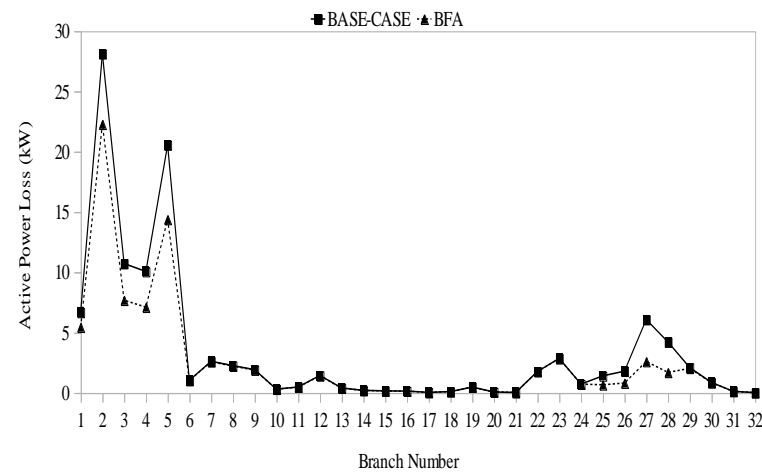

Figure 7. Active power loss reduction using BFA

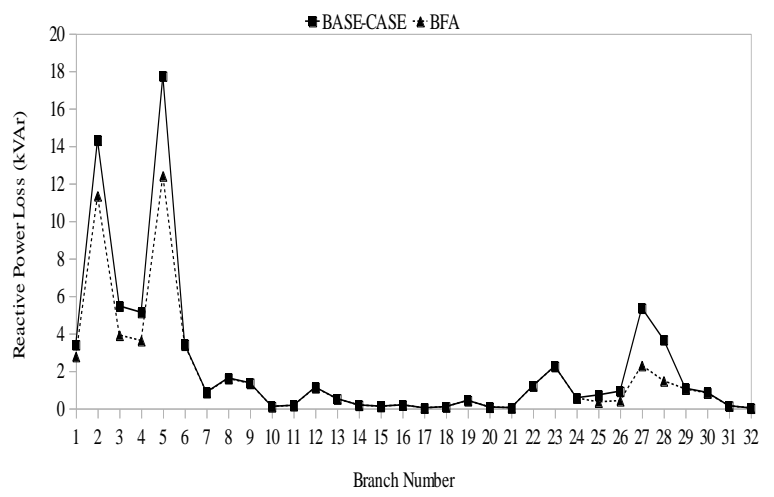

Figure 8. Reactive power loss reduction using BFA 
Performance analysis of the BFA technique for both loading conditions of the network (normal and threequarter) are summarized in tables 2 and 3 respectively.

Table 2. Performance Analysis of BFA for Normal Loading Condition

\begin{tabular}{|c|c|c|}
\hline \multirow{2}{*}{ Parameters } & \multicolumn{2}{|c|}{ Normal Loading (100\%) } \\
\cline { 2 - 3 } & BASE-CASE & BFA [3] \\
\hline $\begin{array}{c}\text { DSTATCOM Position \& } \\
\text { Size (kVAr) }\end{array}$ & - & Bus 30 (2577) \\
\hline Vmin (p.u.) at bus 18 $_{\text {Overall Voltage }}$ & 0.9134 & 0.9428 \\
\hline $\begin{array}{c}\text { Improvement (\%) } \\
\text { Total PLoss (kW) }\end{array}$ & - & 82.88 \\
\hline $\begin{array}{c}\text { PLoss Reduction (\%) } \\
\text { Total QLoss (kVAr) }\end{array}$ & 134.6413 & 132.6283 \\
\hline $\begin{array}{c}\text { QLoss Reduction (\%) } \\
\text { Mean Voltage }\end{array}$ & - & 1.50 \\
\hline Magnitude & 0.9486 & 0.9752 \\
\hline $\begin{array}{c}\text { Computational Time (s) } \\
\text { Oome }\end{array}$ & - & 7.20 \\
\hline
\end{tabular}

Table 3. Performance Analysis of BFA for Three-Quarter Loading

\begin{tabular}{|c|c|c|}
\hline \multirow{2}{*}{ Parameters } & \multicolumn{2}{|c|}{$\begin{array}{c}\text { Three-quarter Loading } \\
(75 \%)\end{array}$} \\
\cline { 2 - 3 } & BASE-CASE & BFA \\
\hline $\begin{array}{c}\text { DSTATCOM Position \& } \\
\text { Size (kVAr) }\end{array}$ & - & Bus 29 (883) \\
\hline $\mathrm{V}_{\text {min }}$ (p.u.) at bus 18 & 0.90363 & 0.9431 \\
\hline $\begin{array}{c}\text { Overall Voltage } \\
\text { Improvement (\%) }\end{array}$ & - & 20.04 \\
\hline $\begin{array}{c}\text { Total PLoss }(\mathrm{kW}) \\
\text { PLoss Reduction (\%) }\end{array}$ & 109.4600 & 82.2493 \\
\hline Total QLoss (kVAr) & 72.9522 & 24.86 \\
\hline QLoss Reduction (\%) & - & 25.6294 \\
\hline $\begin{array}{c}\text { Mean Voltage } \\
\text { Magnitude }\end{array}$ & 0.9621 & 0.9682 \\
\hline Computational Time (s) & - & 6.33 \\
\hline
\end{tabular}

\subsection{0-Bus Canteen Feeder}

The 50-Bus Canteen feeder is an existing local feeder that constitutes part of the Zaria distribution network. The network is characterized by an appreciable number of buses and branches (50-buses and 49-branches), thus making it a relative large network. The single line diagram shown in figure 9 and network data (line and bus) presented in the Appendix are obtained from [12]. The network line voltage, base MVA and total active and reactive loads are given as $11 \mathrm{kV}, 100 \mathrm{MVA}, 0.388 \mathrm{MW}$ and 0.297MVAr respectively.

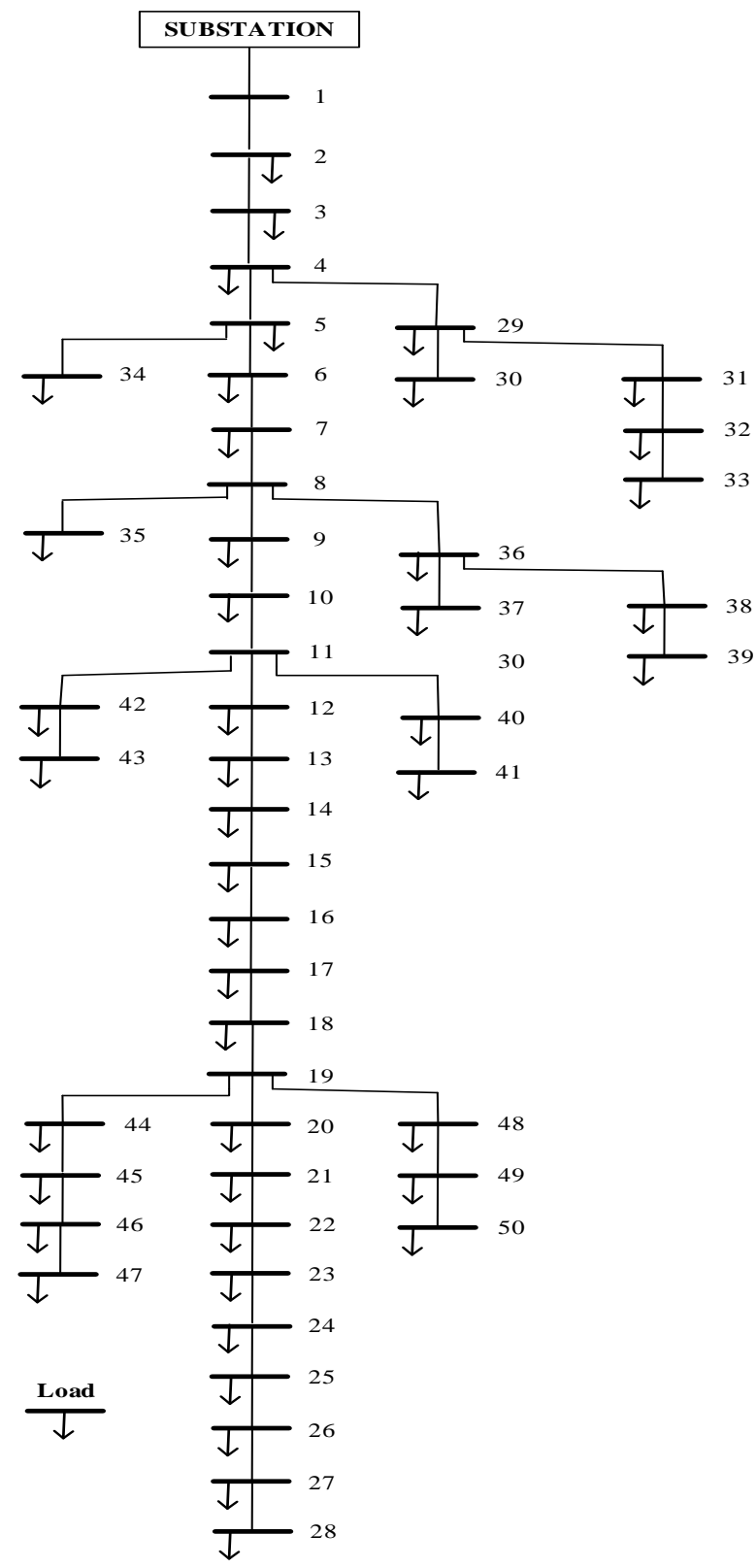

Figure 9. Single line diagram of 50-bus canteen feeder

Under normal loading condition of the feeder, the BFA method obtained 227.8kVAr and bus 41 as the optimum size and position of DSTATCOM. The effect of installing the attained size of DSTATCOM at the optimum bus in terms of voltage profile improvement can be seen clearly in figure 10 .

The feeder minimum bus voltage (at bus 27) has been improved from 0.9892 to 0.9902 p.u, resulting in $6.13 \%$ improvement in overall voltage profile of the feeder. Similarly, the feeder power losses (active and reactive) have been minimized with the installation of DSTATCOM. The active and reactive power losses as shown in figures 11 and 12 have been minimized from their respective base-case values of $2.8066 \mathrm{~kW}$ and $1.7799 \mathrm{kVAr}$ to $2.1655 \mathrm{~kW}$ and $1.3731 \mathrm{kVAr}$ respectively. Therefore yielding a 22.84 and $22.86 \%$ reduction in total active and reactive power losses respectively. Also, the feeder mean voltage magnitude has been improve to 0.9955 from 0.9942 with the incorporation of DSTATCOM. 


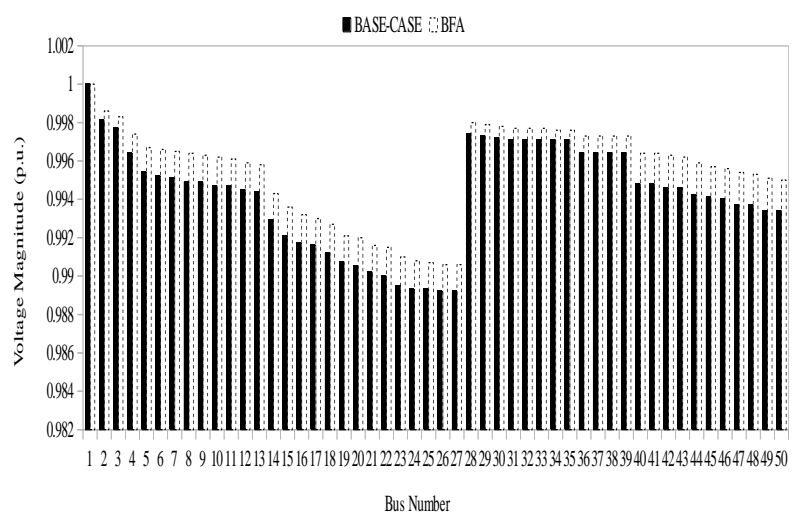

Figure 10. Voltage profile improvement using BFA

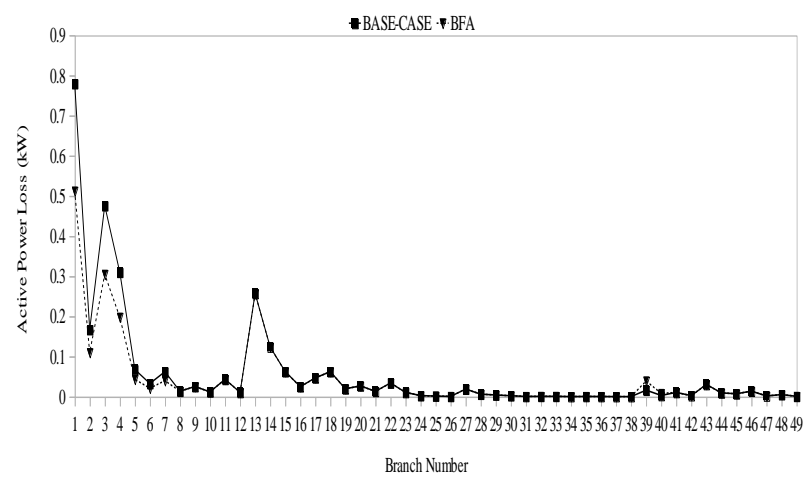

Figure 11. Active power loss reduction using BFA

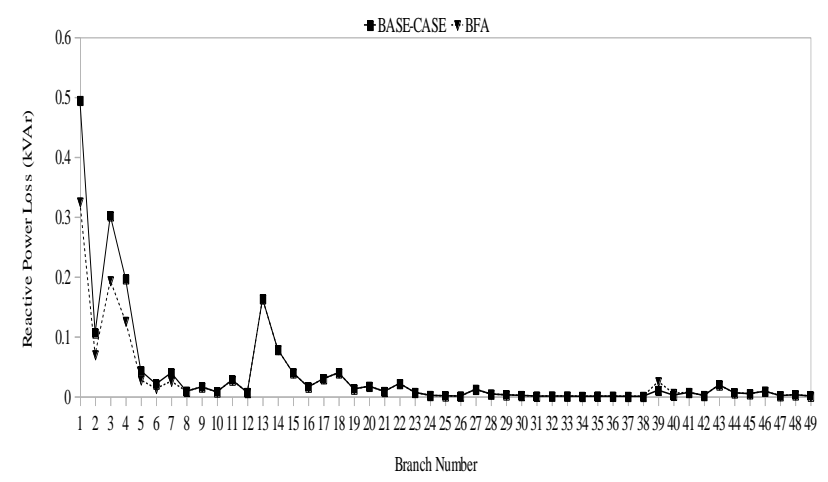

Figure 12. Reactive power loss reduction using BFA

Analysis conducted on the feeder under three-quarter loading condition shows that DSTATCOM size of 149.6kVAr and optimum location of bus 40 were obtained by the proposed technique. The minimum voltage at bus 27 has been enhanced from 0.9919 to 0.9926p.u and the feeder active and reactive losses have been minimized to $1.2625 \mathrm{~kW}$ and $0.8006 \mathrm{kVAr}$ from $1.5725 \mathrm{~kW}$ and $0.9972 \mathrm{kVAr}$ respectively. The voltage profile improvement and the active and reactive power losses reduction achieved in the feeder due to presence of DSTATCOM are shown in figures 13,14 and 15 respectively.

A mere $2.99 \%$ improvement in overall voltage profile of the feeder was recorded as compared to the base-case value. The total active and reactive losses were found to have been reduced by 19.71 and $19.72 \%$ respectively.
Also, the overall voltage magnitude of the feeder was improved to 0.9963 from 0.9960 .

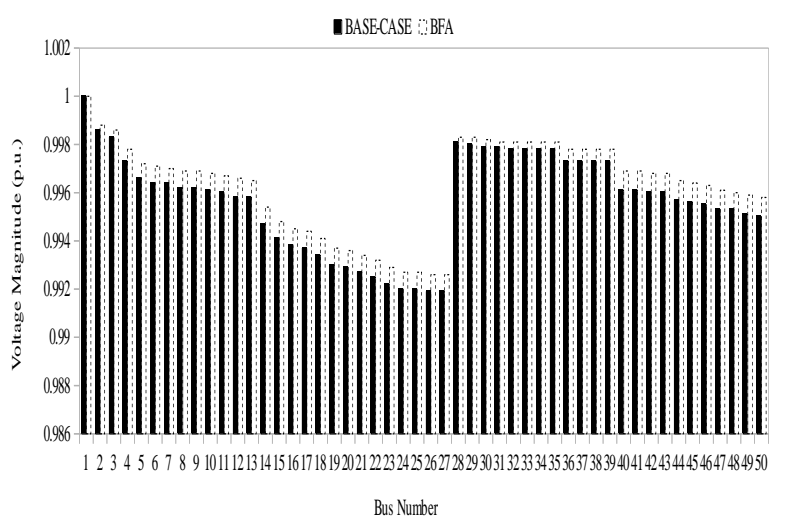

Figure 13. Voltage profile improvement using BFA

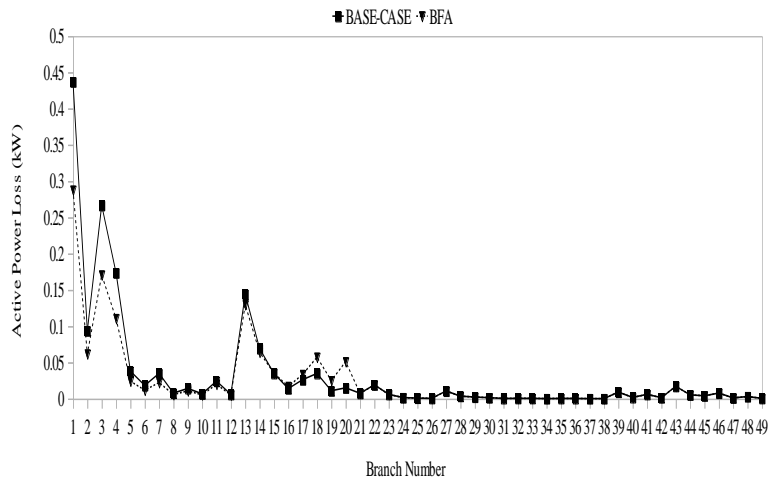

Figure 14. Active power loss reduction using BFA

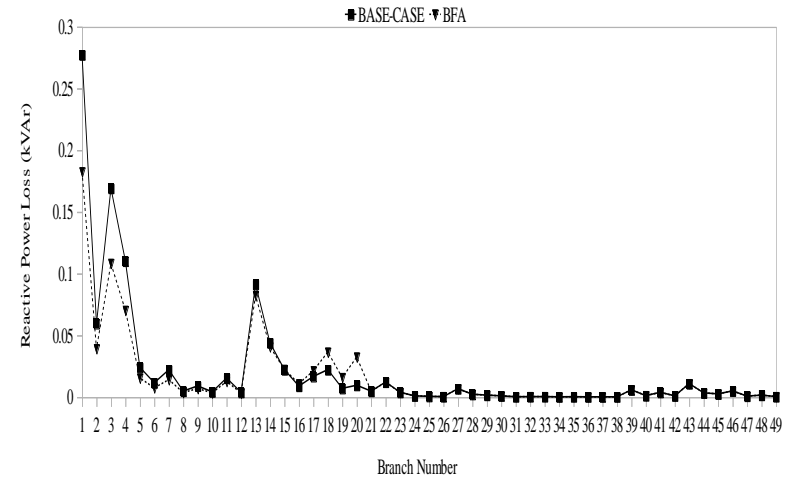

Figure 15. Reactive power loss reduction using BFA

Similarly, the performance analysis of the BFA technique for both loading conditions of the feeder (normal and three-quarter) are summarized in tables 4 and 5 respectively.

\section{CONCLUSION}

This paper examined the ability and effectiveness of the BFA in sizing and site DSTATCOM in an existing local 50-Bus Canteen feeder. The effect of the reactive power injected into the feeder by the DSTACOM has been considered in terms of voltage profile and line losses. Analysis have been performed on the feeder under normal and three-quarter loading conditions, 
while the work has been extended to three-quarter loading condition of the standard test network (IEEE 33-Bus). From the results of a direct power flow, a multi-objective function has been formulated and employed to minimize the total network losses and voltage deviation. The improvements in voltage profile and reductions in power losses recorded by the proposed approach has demonstrated its strength and ability to handle compensation problems in existing distribution networks under different loading conditions. Future work will focus on the validation of the proposed BFA approach by applying a number of recently developed meta-heuristic algorithm in the allocation of multiple DSTATCOMs and other D-FACTS devices in the local network.

Table 4. Performance Analysis of BFA for Normal Loading

\begin{tabular}{|c|c|c|}
\hline \multirow{2}{*}{ Parameters } & \multicolumn{2}{|c|}{ Normal Loading (100\%) } \\
\cline { 2 - 3 } & BASE-CASE & BFA \\
\hline $\begin{array}{c}\text { DSTATCOM Position } \\
\text { \& Size (kVAr) }\end{array}$ & - & Bus 41 (227.8) \\
\hline $\mathrm{V}_{\min }$ (p.u.) at bus 18 & 0.9892 & 0.9906 \\
\hline $\begin{array}{c}\text { Overall Voltage } \\
\text { Improvement (\%) }\end{array}$ & - & 6.13 \\
\hline Total PLoss (kW) & 2.8066 & 2.1655 \\
\hline PLoss Reduction (\%) & - & 22.84 \\
\hline Total QLoss (kVAr) & 1.7799 & 1.3731 \\
\hline QLoss Reduction (\%) & - & 22.86 \\
\hline $\begin{array}{c}\text { Mean Voltage } \\
\text { Magnitude }\end{array}$ & 0.9942 & 0.9955 \\
\hline Computational Time (s) & - & 8.87 \\
\hline
\end{tabular}

Table 5. Performance Analysis of BFA for Three-Quarter Loading

\begin{tabular}{|c|c|c|}
\hline \multirow{2}{*}{ Parameters } & \multicolumn{2}{|c|}{ Normal Loading (75\%) } \\
\cline { 2 - 3 } & BASE-CASE & BFA \\
\hline $\begin{array}{c}\text { DSTATCOM Position \& } \\
\text { Size (kVAr) }\end{array}$ & - & Bus 40 (149.6) \\
\hline Vmin (p.u.) at bus 18 $_{\text {merall Voltage }}$ & 0.9919 & 0.9926 \\
\hline $\begin{array}{c}\text { Overant } \\
\text { Improvement (\%) }\end{array}$ & - & 2.99 \\
\hline Total PLoss $(\mathrm{kW})$ & 1.5725 & 1.2625 \\
\hline PLoss Reduction (\%) & - & 19.71 \\
\hline Total QLoss (kVAr) & 0.9972 & 0.8006 \\
\hline QLoss Reduction (\%) & - & 19.72 \\
\hline $\begin{array}{c}\text { Mean Voltage } \\
\text { Magnitude }\end{array}$ & 0.9960 & 0.9963 \\
\hline Computational Time (s) & - & 8.06 \\
\hline
\end{tabular}

\section{ACKNOWLEDGMENT}

The authors wish to acknowledge the collaborative efforts of the Power Systems Research Groups (PSRGs) of the Department of Electrical Engineering, ABU-Zaria and Saveetha School of Engineering, Saveetha Institute of Medical and Technical Sciences, Chennai, India.

\section{REFERENCES}

[1] Shanmugasundaram, P., and Babu, A. R. (2016). Application of DSTATCOM for Loss Minimization in Radial Distribution System. Paper presented at the Proceedings of the International Conference on Soft Computing Systems, pp. 189-198.

[2] Ebeed, M., Kamel, S., Aleem, S. H. A., and Abdelaziz, A. Y. (2018). Optimal Allocation of Compensators Electric Distribution Network Planning pp. 321-353: Springer.

[3] Musa, U., Bakare, G. A., Mati, A. A., and Mohammad, A. (2018). Radial Distribution Network Enhancement with DSTATCOM using Bacterial Foraging Algorithm. Arid Zone Journal of Engineering, Technology and Environment., 14(2), pp. 1-12.

[4] Devabalaji, K., and Ravi, K. (2015). Optimal size and siting of multiple DG and DSTATCOM in radial distribution system using Bacterial Foraging Optimization Algorithm. Ain Shams Engineering Journal, pp. 1-13.

[5] Yuvaraj, T., Devabalaji, K., and Ravi, K. (2015). Optimal placement and sizing of DSTATCOM using Harmony Search algorithm. Energy Procedia, 79, pp. 759-765.

[6] Musa, U., Bakare, G. A., Mati, A. A., and Mas'ud, A. (2017a). Optimal Placement of D-STATCOM using Quadratic Adaptive Bacterial Foraging Algorithm. Yanbu Journal of Engineering and Sciences, 15(1), 49-59.

[7] Hussain, S. S., and Subbaramiah, M. (2013). An analytical approach for optimal location of DSTATCOM in radial distribution system. Paper presented at the International Conference on Energy Efficient Technologies for Sustainability, pp. 1365-1369.

[8] Jain, A., Gupta, A., and Kumar, A. (2014). An efficient method for D-STATCOM placement in radial distribution system. Paper presented at the 6th IEEE India International Conference on Power Electronics, pp. 1-6.

[9] Gupta, A. R., and Kumar, A. (2015). Energy Savings Using D-STATCOM Placement in Radial Distribution System. Procedia Computer Science, 70, pp. 558-564.

[10] Gupta, A. R., and Kumar, A. (2016). Optimal placement of D-STATCOM using sensitivity approaches in mesh distribution system with time variant load models under load growth. Ain Shams Engineering Journal, pp. 1-17.

[11] Gupta, A. R., and Kumar, A. (2018). Impact of various load models on D-STATCOM allocation in DNO operated distribution network. Procedia Computer Science, 125, pp. 862-870.

[12] Musa, U. (2017). Application of Improved Bacterial Foraging Algorithm to the Optimal Siting and Sizing of DSTATCOM in Radial Distribution Networks. (Published MSc Dissertation), Department of Electrical and Computer Engineering, Ahmadu Bello UniversityZaria, Nigeria.

[13] Sannigrahi, S., and Acharjee, P. (2018). Implementation of crow search algorithm for optimal allocation of DG and DSTATCOM in 
practical distribution system. Paper presented at the 2018 International Conference on Power, Instrumentation, Control and Computing, pp.1-6.

[14] Murty, V. V. S. N., and Kumar, A. (2018). Impact of D-STATCOM in distribution systems with load growth on stability margin enhancement and energy savings using PSO and GAMS. International Transactions on Electrical Energy Systems, pp. 1-24.

[15] Jazebi, S., Hosseinian, S., and Vahidi, B. (2011). DSTATCOM allocation in distribution networks considering reconfiguration using differential evolution algorithm. Energy conversion and Management, 52(7), pp. 2777-2783.

[16] Samal, P., Mohanty, S., and Ganguly, S. (2018). Modeling, optimal sizing, and allocation of DSTATCOM in unbalanced radial distribution systems using differential evolution algorithm. International Journal of Numerical Modelling: Electronic Networks, Devices and Fields, pp. 1-14.

[17] Sedighizadeh, M., and Eisapour-Moarref, A. (2017). The Imperialist Competitive Algorithm for Optimal Multi-Objective Location and Sizing of DSTATCOM in Distribution Systems Considering Loads Uncertainty. INAE Letters, 2(3), pp. 83-95.

[18] Devabalaji, K., Yuvaraj, T., and Ravi, K. (2016). An efficient method for solving the optimal sitting and sizing problem of capacitor banks based on cuckoo search algorithm. Ain Shams Engineering Journal, pp.1-9.

[19] Bagheri Tolabi, H., Ali, M. H., and Rizwan, M. (2015). Simultaneous Reconfiguration, Optimal Placement of DSTATCOM, and Photovoltaic Array in a Distribution System Based on Fuzzy-ACO Approach. Sustainable Energy, IEEE Transactions on, 6(1), pp. 210-218.

[20] Devi, S., and Geethanjali, M. (2014). Application of modified bacterial foraging optimization algorithm for optimal placement and sizing of distributed generation. Expert Systems with Applications, 41(6), pp. 2772-2781.

[21] Taher, S. A., and Afsari, S. A. (2014). Optimal location and sizing of DSTATCOM in distribution systems by immune algorithm. International Journal of Electrical Power \& Energy Systems, 60, pp. 3444.

[22] Farhoodnea, M., Mohamed, A., Shareef, H., and Zayandehroodi, H. (2013). Optimum DSTATCOM placement using firefly algorithm for power quality enhancement. Paper presented at the 7th IEEE International Conference on Power Engineering and Optimization, pp. 98-102.

[23] Umar, M., Bakare, G. A., Shehu, M. A., and Abubakar, U. (2017). DSTATCOM placement in distribution systems using weighted Artificial Fish Swarm Algorithm. Paper presented at the 3rd IEEE International Conference on Electro-Technology for National Development, pp. 926-931.

[24] Kiani, M., Mohammadi, S. M. A., and Gharaveisi, A. A. (2013). A bacterial foraging optimization approach for tuning type-2 fuzzy logic controller. Turkish Journal of Electrical Engineering \& Computer Sciences, pp. 263-273.

[25] Passino, K. M. (2002). Biomimicry of bacterial foraging for distributed optimization and control. Control Systems, IEEE, 22(3), pp. 52-67.

[26] Passino, K. M. (2012). Bacterial foraging optimization. Innovations and Developments of Swarm Intelligence Applications, 219.

[27] Xing, B., and Gao, W.-J. (2014). Innovative computational intelligence: a rough guide to 134 clever algorithms: Springer.

[28] Ali, E., and Abd-Elazim, S. (2013). Bacteria Foraging: A New Technique for Optimal Design of FACTS Controller to Enhance Power System Stability. WSEAS Transactions on Systems, 12(1), pp. 42-52.

[29] Boussaïd, I., Lepagnot, J., and Siarry, P. (2013). A survey on optimization metaheuristics. Information Sciences, 237, pp. 82-117.

[30] Musa, U., Mohammed, A., Umar, A., and Olaniyan, A. A. (2017b). Bacterial Foraging Algorithm Based Scheduling for Optimal Siting and Sizing of UPQC in Standard IEEE 33-Bus Test Network. Paper presented at the 2nd International Conference on Green Research, Innovation and Sustainable Development, pp. 369-374. 


\section{APPENDIX}

Line and bus data for 50-Bus Canteen Feeder.

\begin{tabular}{|c|c|c|c|c|c|c|}
\hline Branch No. & From Bus & To Bus & $\mathrm{R}(\Omega)$ & $\mathrm{X}(\Omega)$ & $\mathrm{P}_{\mathrm{D}}(\mathrm{kW})$ & $\mathrm{Q}_{\mathrm{D}}(\mathrm{kVAr})$ \\
\hline 1 & 1 & 2 & 0.3871 & 0.2456 & 0 & 0 \\
\hline 2 & 2 & 3 & 0.0829 & 0.0526 & 6.48 & 4.86 \\
\hline 3 & 3 & 4 & 0.3318 & 0.2105 & 3.24 & 2.43 \\
\hline 4 & 4 & 5 & 0.2489 & 0.1579 & 3.24 & 2.43 \\
\hline 5 & 5 & 6 & 0.0553 & 0.0351 & 6.48 & 4.86 \\
\hline 6 & 6 & 7 & 0.0277 & 0.0175 & 6.48 & 4.86 \\
\hline 7 & 7 & 8 & 0.0553 & 0.0351 & 6.48 & 4.86 \\
\hline 8 & 8 & 9 & 0.0277 & 0.0175 & 6.48 & 4.86 \\
\hline 9 & 9 & 10 & 0.0553 & 0.0351 & 6.48 & 4.86 \\
\hline 10 & 10 & 11 & 0.0277 & 0.0175 & 6.48 & 4.86 \\
\hline 11 & 11 & 12 & 0.1106 & 0.0702 & 3.24 & 2.43 \\
\hline 12 & 12 & 13 & 0.0277 & 0.0175 & 9.72 & 7.29 \\
\hline 13 & 13 & 14 & 0.7742 & 0.4912 & 3.24 & 2.43 \\
\hline 14 & 14 & 15 & 0.3871 & 0.2456 & 9.72 & 7.29 \\
\hline 15 & 15 & 16 & 0.2212 & 0.1403 & 16.20 & 12.15 \\
\hline 16 & 16 & 17 & 0.1106 & 0.0701 & 3.24 & 2.43 \\
\hline 17 & 17 & 18 & 0.2212 & 0.1403 & 16.20 & 12.15 \\
\hline 18 & 18 & 19 & 0.3871 & 0.2456 & 16.20 & 12.15 \\
\hline 19 & 19 & 20 & 0.1659 & 0.1052 & 16.20 & 12.15 \\
\hline 20 & 20 & 21 & 0.3318 & 0.2105 & 6.48 & 4.86 \\
\hline 21 & 21 & 22 & 0.1936 & 0.1228 & 6.48 & 4.86 \\
\hline 22 & 22 & 23 & 0.6083 & 0.3859 & 16.20 & 12.15 \\
\hline 23 & 23 & 24 & 0.3318 & 0.2105 & 16.20 & 12.15 \\
\hline 24 & 24 & 25 & 0.1659 & 0.1052 & 16.20 & 12.15 \\
\hline 25 & 25 & 26 & 0.3318 & 0.2105 & 6.48 & 4.86 \\
\hline 26 & 26 & 27 & 0.3595 & 0.2281 & 9.72 & 7.29 \\
\hline 27 & 3 & 28 & 0.4701 & 0.2982 & 9.72 & 7.29 \\
\hline 28 & 28 & 29 & 0.2212 & 0.1403 & 6.48 & 4.86 \\
\hline 29 & 29 & 30 & 0.1935 & 0.1228 & 9.72 & 7.29 \\
\hline 30 & 30 & 31 & 0.1935 & 0.1228 & 3.24 & 2.43 \\
\hline 31 & 31 & 32 & 0.0277 & 0.0175 & 6.48 & 4.86 \\
\hline 32 & 32 & 33 & 0.1106 & 0.0701 & 6.48 & 4.86 \\
\hline 33 & 33 & 34 & 0.2212 & 0.1403 & 6.48 & 4.86 \\
\hline 34 & 34 & 35 & 0.0553 & 0.0351 & 6.48 & 4.86 \\
\hline 35 & 4 & 36 & 0.0553 & 0.0351 & 6.48 & 4.86 \\
\hline 36 & 36 & 37 & 0.0553 & 0.0351 & 6.48 & 4.86 \\
\hline 37 & 37 & 38 & 0.0553 & 0.0351 & 3.24 & 2.43 \\
\hline 38 & 38 & 39 & 0.0277 & 0.0175 & 3.24 & 2.43 \\
\hline 39 & 8 & 40 & 0.1382 & 0.0877 & 6.48 & 4.86 \\
\hline 40 & 40 & 41 & 0.0277 & 0.0175 & 3.24 & 2.43 \\
\hline 41 & 41 & 42 & 0.1106 & 0.0702 & 6.48 & 4.86 \\
\hline 42 & 42 & 43 & 0.0277 & 0.0175 & 3.24 & 2.43 \\
\hline 43 & 43 & 44 & 0.4148 & 0.2631 & 9.72 & 7.29 \\
\hline 44 & 44 & 45 & 0.1659 & 0.1053 & 3.24 & 2.43 \\
\hline 45 & 45 & 46 & 0.1382 & 0.0877 & 16.20 & 12.15 \\
\hline 46 & 46 & 47 & 0.4977 & 0.3158 & 16.20 & 12.15 \\
\hline 47 & 47 & 48 & 0.1383 & 0.1000 & 9.72 & 7.29 \\
\hline 48 & 48 & 49 & 1.0000 & 0.5000 & 9.72 & 7.29 \\
\hline 49 & 49 & 50 & 0.5000 & 0.3000 & 9.72 & 7.29 \\
\hline
\end{tabular}

